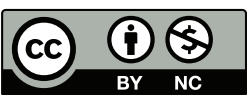

Revista Galega de Administración Pública, EGAP Núm. 60_xullo-decembro 2020 | pp. 265-269 Santiago de Compostela, 2020

https://doi.org/10.36402/regap.v0i60.4693

(c) Noelia Betetos Agrelo

ISSN-L: 1132-8371

Recibido: 11/12/2020 | Aceptado: 14/12/2020 Editado baixo licenza Creative Commons Atribution 4.0 International License

\section{Los servicios sociales en el S. XXI: nuevas tipologías y nuevas formas de prestación}

Regap

NOELIA BETETOS AGRELO

Investigadora da Área de Dereito Administrativo

Universidade de Santiago de Compostela

noelia.betetos.agrelo@usc.es

GARRIDO JUNCAL, A.: Los servicios sociales en el S. XXI: nuevas tipologías y nuevas formas de prestación, Thomson Reuters-Aranzadi, Cizur Menor, 2020, 313 pp. ISBN: 978-84-91352-95-2.

Esta monografía constitúe a continuación do estudo acerca da configuración do réxime xurídico dos servizos sociais no ordenamento xurídico español. O dito traballo foi iniciado pola autora con ocasión da súa tese de doutoramento, culminada con grande éxito no ano 2015. O labor efectuado na súa monografía é encomiable, pois existen poucos estudos que se decanten por abordar como tema central a análise do réxime xurídico actual dos servizos sociais, dada a súa enorme complexidade e a escasa preocupación que o lexislador prestou a esta cuestión ata épocas recentes. 
O volume estrutúrase en catro capítulos nos cales se acomete de xeito sistemático o estudo da evolución histórica no que respecta á configuración xurídica dos servizos sociais para confrontala a posteriori co estado actual da disciplina. No capítulo segundo, é posible atopar unha elaborada construción dogmática en que a profesora Garrido Juncal trata de introducir o lector na conceptualización do termo "servizos sociais", así como definir cal é a natureza xurídica que reviste esta modalidade de servizo público. No capítulo terceiro, analízase o marco xurídico en que se enmarcan os servizos sociais, desde o seu encadramento no réxime xurídico constitucional, pasando pola análise da repartición competencial en materia de servizos sociais entre os diferentes niveis de goberno, con especial referencia ás leis autonómicas que regulan esta tipoloxía de servizos. Finalmente, o último capítulo, en consonancia co anterior, remata coa exposición detallada do réxime xurídico do concerto social a través dun exame transversal dos elementos obxectivos, subxectivos e procedementais que caracterizan esta institución.

Cómpre comezar esta recensión sinalando que a investigación, que neste sentido chega nun momento moi pertinente, afronta a análise crítica dos principais desafíos a que se enfrontan os servizos sociais na actualidade. Todo iso examinado desde unha óptica que permite establecer unha visión global acerca de como se desenvolveu o proceso evolutivo da institución dos servizos sociais, o que sen dúbida é esencial para comprender cales foron os factores decisivos no que ao atraso da súa consolidación se refire.

Certamente, tal como se logra albiscar no traballo, o carácter cíclico que constitúe a esencia das recesións económicas como a acaecida no ano 2008 de cuxos efectos aínda non estamos completamente repostos, así como a frustración no obxectivo de recuperación financeira lograda ata a actualidade que se viu dificultada a causa das secuelas que xa se empezan a manifestar a consecuencia da pandemia do COVID-19, fan que a implementación dun sistema de servizos sociais sólido sexa todo un reto para o conxunto das nosas administracións públicas. Así, a premisa que se extrae desta primeira aproximación pódese sintetizar baixo a idea de que os períodos de dificultade económica son unha das principais causas que inciden no grao de protección que se lles dispensa aos dereitos fundamentais socioeconómicos, coa conseguinte afectación negativa ao ámbito dos servizos sociais.

Da argumentación exposta despréndese que o núcleo central que rodea a construción dunha teoría solvente que teña como obxecto os servizos sociais se ve, a miúdo, frustrado pola posición que se lle outorga a esta tipoloxía de servizos públicos dentro do conxunto de prestacións garantidas no marco do Estado de benestar. Resulta evidente, polo tanto, que os servizos sociais viñeron ocupando tradicionalmente o piar menos evolucionado do cuarteto que conforma xunto á sanidade, á educación e á seguridade social. O certo é que, en contraposición á fortaleza e á estabilidade que caracterizan os servizos públicos anteriormente citados, as prestacións asistenciais, por outro lado, dependen en gran medida da situación económica e da dispoñibilidade orzamentaria existente en cada momento, de tal forma que veñen resignándose a 
ocupar unha sorte de categoría secundaria cuxo fin busca cubrir as necesidades que non atopan cabida na educación, na sanidade e na seguridade social.

O estudo do primeiro capítulo permitiralle ao lector, tal como o fai a autora, cuestionarse acerca do feito de se, e en que medida, o réxime xurídico dos servizos sociais se ve afectado polas tendencias políticas e sociais preeminentes na actualidade que se decantan pola destrución do sistema existente ou ben se debe avogar por unha axeitada reestruturación do modelo de Estado de benestar. A profesora fai fincapé no feito de que os servizos sociais, e máis especificamente no tocante ao nivel de garantía asistencial que se vai reclamar a través deste tipo de prestacións, vén innegablemente ligado ao contexto social, político e económico presente en cada momento, o que exixe un esforzo constante por parte das institucións públicas, que teñen que adaptarse á situación cambiante. Neste sentido, aínda que resulta innegable que a dispoñibilidade orzamentaria é un elemento clave na fixación do alcance dos servizos sociais que se lles van brindar aos cidadáns en cada momento histórico, tamén convén destacar que lles corresponde aos poderes públicos garantir, en calquera caso, un contido prestacional mínimo que vén ligado á declaración constitucional do Estado social e que se deberá manter con independencia da situación financeira das arcas públicas. Finalmente, dentro do contido da primeira parte da obra, resta destacar as interesantes observacións formuladas nas que se teoriza sobre o valor que se lle debe dar á recente proliferación de disposicións normativas ditadas neste ámbito, mediante a análise dos motivos a que responde a centralidade que esta materia tivo en épocas recentes e se con ela se está a tratar de paliar as insuficiencias estruturais que presentaba o sistema ata a actualidade.

O capítulo segundo aborda unha tarefa arduamente complexa, como é sempre o conceptualización das institucións xurídicas ${ }^{1}$, acrecentada esta dificultade no caso dos servizos sociais polo feito de estarmos ante unha acepción polisémica, o que supón que nela atopen cabida diferentes modalidades de prestacións asistenciais. Ao longo do capítulo, a autora avoga pola necesidade de restrinxir o concepto de servizos sociais, afirmando que, a miúdo, o termo se emprega para describir unha realidade tan ampla que practicamente atopan acomodo nela calquera tipo de política pública de orde social, laboral, cultural, educativa ou calquera outra de análoga natureza, o que resulta contraproducente cando se trata de materializar estas políticas ou directrices en verdadeiras prestacións en favor dos cidadáns. Pola súa vez, o lector poderá beneficiarse do labor de clasificación sempre de grande utilidade para organizar algúns dos conceptos esenciais arredor da configuración do réxime xurídico dos servizos sociais.

Efectuada a antedita tarefa de sistematización e conceptualización, a autora culmina o capítulo abordando dúas cuestións que incitan á reflexión. Por unha banda, analiza cal é a posición xurídica que ocupa o cidadán nas relacións que o unen coa Administración pública, como destinatario o primeiro e responsable a segunda na

1 Especial mención no ámbito da formación de conceptos xurídicos propios do dereito público merece a monografía de DÍEZ SASTRE, S., La formación de conceptos en el Derecho Público. Un estudio de metodología académica: definición, funciones y criterios de formación de los conceptos jurídicos, Marcial Pons, Madrid, 2018. Neste sentido, a mesma autora destaca a complexidade inherente á construción dogmática no ámbito xurídico, dificultada pola imposibilidade de abranguer a totalidade das fontes dispoñibles, pero tan necesaria para o progreso da ciencia xurídica. 
prestación dos servizos sociais. E, por outra banda, na última epígrafe o lector pode afondar nas observacións formuladas pola profesora Garrido Juncal sobre a natureza xurídica que cómpre recoñecerlles aos servizos sociais, así como os argumentos esgrimidos pola doutrina en relación coa súa eventual cualificación como servizo público.

Seguidamente, o capítulo terceiro dedícase á revisión do marco normativo en que se encadra a regulación dos servizos sociais. Pola súa parte, este atópase divido en dúas epígrafes diferenciadas nas cales se aborda o estudo da constitucionalización dos servizos sociais a partir da Carta Magna de 1978, para a continuación examinar na segunda epígrafe as disposicións autonómicas vixentes que regulan esta cuestión, así como as tensións competenciais que se produciron tras as iniciativas do lexislador estatal nun ámbito cuxa competencia corresponde en exclusiva ás comunidades autónomas (art. $148.1 .20^{\circ} \mathrm{CE}$ ).

Certamente, en España a configuración constitucional do Estado social non é unha cuestión exenta de dificultades. Con carácter xeral, a lectura da nosa Carta Magna permite individuar numerosas ordes dirixidas aos poderes públicos cuxo contido incorpora verdadeiros mandatos destinados á tutela daqueles sectores da poboación que se atopan máis desfavorecidos ou en situación de vulnerabilidade. Non obstante, a redacción ambigua e as cuantiosas remisións fan que estas obrigas impostas a poderes públicos se dilúan, quedando reconducida a meros principios programáticos que deben inspirar o ordenamento xurídico, sen recoñecérselles un contido obrigacional concreto. No que respecta ao estudo da regulación vixente, a totalidade das nosas comunidades autónomas asumiron, en réxime de exclusividade, a aprobación de disposicións cuxo obxectivo principal se centra na construción dun réxime xurídico completo en materia de servizos sociais. Porén, debe salientarse a tendencia crecente do lexislador nacional de "invadir" este marco competencial propio das autonomías, que, pola súa vez e de forma sorprendente, adoptaron unha actitude pasiva respecto a estas intrusións, limitándose a adaptar a súa normativa propia ás novas directrices consagradas nas disposicións estatais².

O último capítulo céntrase no estudo das formas de xestión dos servizos sociais. Como xa resulta de sobra coñecido, no ámbito específico desta tipoloxía de servizos conflúen a iniciativa pública coa errogación privada das prestacións e demais beneficios de carácter asistencial que integran o contido da institución xurídica obxecto de análise. A conciliación das dúas formas de prestación non presenta neste sector de actividade ningunha problemática desde o punto de vista do respecto ao principio de libre competencia, fortemente implementado a partir do proceso de liberalización

2 Con carácter xeral, a base competencial a que recorre o lexislador nacional cando desexa acometer algunha intervención lexislativa en materia de servizos sociais é a sinalada no artigo 149.1.1. ${ }^{\circ}$ da CE, que lle atribúe ao Estado a competencia exclusiva para a "regulación das condicións básicas que garantan a igualdade de todos os españois no exercicio dos dereitos e no cumprimento dos deberes"; así o fixo, por exemplo, con ocasión da aprobación da Lei 39/2006, do 14 de decembro, de promoción da autonomía persoal e atención ás persoas en situación de dependencia. Este feito parece denotar a vontade do lexislador estatal de irromper nun ámbito de actuación que tradicionalmente veu desenvolvido polas comunidades autónomas, sen prexuízo das eventuais transferencias de fondos proporcionadas para financiar esta actividade prestacional. O feito de que se recorra a esa habilitación constitucional tan abstracta e pouco conectada, a priori, cos servizos sociais pode ser un elemento a tomar en consideración para testemuñar que o Estado invadiu competencias propias das autonomías, xa que se se atopase formalmente lexitimado para abordar este labor se ampararía nalgunha outra base de entre as expresamente previstas no artigo 149 da Carta Magna. 
económica instado polas autoridades europeas. En concreto, a compatibilidade dos dous réximes, o privado, suxeito ás regras de mercado, e o público, financiado con cargo ás dispoñibilidades orzamentarias das administracións, xustifícase na relevancia social que subxace á prestación destes servizos.

Así, a normativa actual que regula as formas de xestión dos servizos sociais é o resultado dun conxunto de acontecementos que influíron de forma significativa na normativa vixente. O primeiro deles non pode ser outro que a aprobación polas institucións europeas do Cuarto Paquete de Directivas sobre contratación pública, cuestión intimamente ligada ao segundo elemento, que vén marcado polo xeito de transposición das mencionadas disposicións ao ordenamento xurídico español. Respecto a este punto, debo limitar as miñas reflexións a apuntar que a incorporación das anteriores previsións implica a eliminación do contrato de xestión de servizos públicos e, dentro deste, da modalidade do concerto, ferramenta que tradicionalmente lles daba forma aos contratos que tiñan como obxecto a prestación dos servizos sociais. Finalmente, o último fito que caracteriza esta nova regulación é a supervivencia da figura do concerto social nas lexislacións das comunidades autónomas, aspecto este último que é analizado con plena solvencia na obra, á cal nos remitimos para afondar máis sobre o tema.

Por todo o exposto, cabe concluír que a lectura do libro analizado resulta sumamente recomendable a todo tipo de público que desexe formarse na materia, xa que lles proporciona aos lectores unha visión global acerca do panorama xurídico vixente e dos retos a que se enfrontan os servizos sociais na actualidade. Todo iso analizado cun enfoque exhaustivo que garante ao lector a certeza de adquirir o coñecemento necesario sobre os sucesivos cambios que acaeceron neste eido durante a paulatina evolución da institución xurídica.

En definitiva, a obra resulta destacable non só pola gran brillantez expositiva da súa redacción, senón tamén pola accesibilidade con que se expón unha cuestión de tanto calado como a é a construción dogmática dos servizos sociais. Iso fai da monografía un instrumento sumamente aconsellable para aqueles que desexen acometer o estudo do réxime xurídico dos servizos sociais a través da análise da súa evolución histórica e da normativa vixente, así como dos desafíos e perspectivas que cómpre superar no futuro para o progreso nesta disciplina. 
